\title{
Design on the Incentive Contract of University Achievements Commercialization Offices Based on Principal-Agent Theory
}

\author{
Meifang $\mathrm{Li}^{1}$, Yongxiang $\mathrm{Zhao}^{2}$, Feng $\mathrm{Shi}^{3}$ \\ ${ }^{1}$ School of Management, Wuhan University of Technology, Wuhan, China; ${ }^{2}$ Wuhan University of Technology, School of Computer \\ Science and Technology, Wuhan, China; ${ }^{3}$ Wuhan Academy of Social Sciences, Wuhan, China. \\ Email: poplimeif@126.com, zhaosanhe@263.net, sf196293@163.com
}

Received October $13^{\text {th }}, 2009$; revised November $21^{\text {st }}$, 2009; accepted December $30^{\text {th }}, 2009$.

\begin{abstract}
Based on principal-agent theory, an incentive contract model of university achievements commercialization offices $(U A C O)$ was constructed in this paper, and an optimal incentive contract between university and UACO was researched into. The conclusion indicates that many factors, such as working ability, working willingness, risk aversion degree of UACO, as well as the outside uncertain factors and so on, have important influences on the contract design. The efficiency of commercialization of university inventions has a squared forward growth relation with working ability, a direct proportion with working willingness, and has an inverse proportion with risk aversion degree of UACO and with outside uncertainty. Additionally, the level of hard working of UACO under the condition of information asymmetry is strictly less than that of information symmetry.
\end{abstract}

Keywords: University Achievements Commercialization Offices (UACO), Achievements Commercialization, Principal-agent, Incentive Contract

\section{Introduction}

In order to promote the commercialization of research findings, and to raise technology transfer rate, almost all the universities in China have set up a department for connecting among industry, university and research institute. The department usually conducts the work of patents applications and achievements transformation for teachers and scientists of the university. At present, there is still not uniform name for this department in Chinese universities, some of them is called university industry management office, some is named S\&T achievements transfer office, and still others is known as technology transfer office and so on. In this paper it is named university achievements commercialization office (UACO) for the sake of convenience.

In the recent years, the transformation of achievements of universities has been attached great importance in all levels of the governments in China, and universities also offers a series of incentives for the commercialization of research findings. However, the result of transformation is still not desirable. The reasons would be various but UACO has to bear the blame, because it plays an impor- tant role of bridge and link between university and businesses. But the cause from UACO hasn't been given enough attention. At the present time there is less research focusing on this problem domestically, and the research has been existed abroad but numerically small. For example, it is fully affirmed the important roles of UACO in the papers of Leitch, et al [1] and Colm, et al [2]. They hold that UACO should and could play an important and unique role in the process of the commercialization of university achievements. Donald, et al [3] and Swamidass, et al [4] proposed that inappropriate administrative staff and irrational reward system are the major hindrances to the achievements transformation of university. Chapple et al. pointed out that it is very important for university technology transfer officers and managers in England to upgrade business skills and capabilities in order to increase university technology transfer efficiently [5]. Markman et al. showed that commercialization outcomes would be enhanced when UACO employ diverse licensing strategies, enjoy greater autonomy, and be compensated well [6]. In fact, there is a principal-agent relationship between university and UACO, and commercialization efficiency could be en- 
hanced through the design of incentive contract of these two parts, but scholars in China and abroad pay little attention to it. In this paper, principal-agent theory is deployed to construct a principal-agent model between university and UACO, so as to design an incentive contract thereby increasing the efficiency of commercialization, and hardening society-serving function of universities.

\section{The Principal-Agent Relations of University Achievements$$
\text { Commercialization and the Necessity }
$$ of Incentive Contract Designing}

\subsection{The Principal-Agent Relations of University Achievements Commercialization}

Any interrelation involving asymmetric information could be called principal-agent relation from the sense of economics. One party with information superiority is agent, and the other at information disadvantage is principal. Furthermore, personal information of agent has some influence on the interests of principal who is uninitiated [7].

From the perspective that UACO is commissioned to commercialize achievements and patents of university scientists, there is a principal-agent relation between university and UACO. In case of information asymmetry, UACO has private information, and this information such as how hard it works, has a great impact on the interests of university, for example impacting on the commercialization efficiency of the university.

According to the theory of information economics, information asymmetry is easy to result in moral hazard problem. In the principal-agent relation between university and UACO, university (as principal) were not accessible to direct observation on which level of hard working UACO had selected, and what university could observe was another variables, such as technology transfer rate and so on. But the rate of technology transfer is determined by the level of hardworking and other outside random factors together. Consequently, there is an incomplete information game with uncertainty but couldn't be supervisory [8]. In this game, the task confronting university (principal) is how to design an incentive contract to motivate UACO (agent) select behavior that fit for the interests of the university.

\subsection{The Necessity of Incentive Contract Designing}

To some extent, UACO performs practically no function in the universities in China, and it is lack of influence and ability in the work of technology transfer. Many university scientists are reluctant to commercialize their achievements through UACO, but to establish communication with corporations by themselves or just declare their achievements for prize and acknowledgment and then put them on the shelf.

There are many causes giving rise to this situation. First, staff structure is unfit for requirements of commercialization. The officers in UACO have, in many cases, neither technical advantages nor marketing skills, and have not the competence to be engaged in the work of achievements commercialization. Second, the compensation system is not rational. What UACO basically executes is fixed salary in China for a long time, and there is no difference for officers between good business and bad one, no difference between hardworking and slacking. As a result, there is no enthusiasm for officers of UACO to involve in the work of commercialization. Third, it lacks the necessary autonomy in UACO. A great majority of UACO in China are attached to departments of Science \& Technology of universities. Officers work in UACO just as a matter of routine, and it is absence of mental stress for their jobs. Fourth, it is lack of active action of hunting for market demands. The outdated way of working that doing nothing but waiting for buyer cannot meet the needs of a market economy.

Consequently, in order to make UACO play a greater role for universities in serving local economy and in pressing ahead with combination of industry and university, the urgent task is to introduce market mechanism into UACO, to reform the existing compensation system and grant more autonomy, and to enhance enthusiasm for the work of commercialization. Under these circumstances, it is urgently necessary for universities to design an optimal contract, so as to encourage UACO to work doubly hard on enhancing the efficiency of commercialization of research findings in universities.

\section{Design on Incentive Contract of University Achievements Commercialization Offices}

On the basis of the preceding analysis on the principalagent relation between university and UACO, and supposing that principal and agent are based on rational-economic man hypothesis, whether agent choose to work hard to enhance the efficiency of achievements transformation or not is totally dependent upon the incentive contract that university provided. According to the parameter method of distribution function brought forward by Mirrlees [9] and Holmstrom [10], the principal-agent model between university and UACO could be constructed.

\subsection{Construction of Incentive Model for UACO}

For the convenience of research working, and in a situation of no influence on conclusion, the following assumptions are proposed, supposing $e$ is a one-dimension variable of hardworking level of agent (UACO), and it is related to initiative and resources injection of UACO. The parameter $k$ is representative the coefficient of 
working capability of UACO, and it is relative to management ability, scientific and technical level, marketing skills of UACO. Parameter $\theta$ denotes uncertain factors that influences achievements transformation of universities, and it is a normal approximation distribution and let it be a random variable with mean of 0 and variance of $\sigma^{2}$. Then the output of UACO could be expressed with the following linear function:

$$
\pi=k e+\theta
$$

Here, $E \pi=k e, \operatorname{var}(\pi)=\operatorname{var}(\theta)=\sigma^{2}$. That is to say, the level of hardworking and the level of working capability determine the mean of output of UACO, and the variance of output is only connected with that of endogenous random variable. Here, $E$ represents mathematic expectation operator, and var means variance.

Supposing that principal (university) is risk-neutral and agent (UACO) is risk-avoidance, and optimal contract is linear under the hypothesis of rational-economic agent [11], then linear contract is considered as following

$$
s(\pi)=\alpha+\beta \pi
$$

$s(\pi)$ refers to income of UACO (or its employees), and $\alpha$ is fixed salary. $\beta$ is the share of UACO in its outputs, it could be also called incentive intensity that university provides to UACO. A further formula could be gotten if expression (2) is substituted with (1), that is

$$
s(\pi)=\alpha+\beta(k e+\theta)
$$

then the revenue of university could be expressed by $v(\pi, s(\pi))=\pi-s(\pi)=-\alpha+(1-\beta)(k e+\theta)$, and expected utility equals to expected revenue according to the assumption of risk-neutral for principal (university), that is

$$
\begin{aligned}
& E v(\pi, s(\pi))=E[-\alpha+(1-\beta)(k e+\theta)] \\
= & -\alpha+(1-\beta) k e
\end{aligned}
$$

Let $\rho$ be the level of utter risk avoidance, and $\rho>0$. To express risk cost of agent with $r(\rho)$, then $r(\rho)=\rho \beta^{2} \sigma^{2} / 2$. If $c(e)$ refers to the cost of working hard of UACO, and $c(e)=b e^{2} / 2$ is supposed for simplifying the problem. Here, $b$ refers to cost coefficient and $b>0$. Therefore, the deterministic equivalence income of UACO is

$$
\begin{aligned}
& W=E\left[s(\pi)-c(e)-\rho \beta^{2} \sigma^{2} / 2\right] \\
& =\alpha+\beta k e-b e^{2} / 2-\rho \beta^{2} \sigma^{2} / 2
\end{aligned}
$$

Let $\bar{w}$ be conservative income of agent, then individual rationality (IR) of agent could be expressed by

$$
\alpha+\beta k e-b e^{2} / 2-\rho \beta^{2} \sigma^{2} / 2 \geq \bar{w}
$$

and the incentive compatibility (IC) of agent is

$$
e \in \arg \max \left\{\alpha+\beta k e-b e^{2} / 2-\rho \beta^{2} \sigma^{2} / 2\right\}
$$

\subsection{Solution of the Incentive Model}

In order to compare expected income of university and UACO under the condition of asymmetric with that of symmetric information, the solution of incentive model under the condition of symmetric information is necessary to be discussed in brief.

1) Optimal contract under the condition of information symmetry

The level of hardworking of agent could be observed by principal under the condition of symmetric information. The incentive compatibility (IC) of agent at the moment does not work because any level of $e$ could be gotten and realized through an enforced contract meeting the requirement of individual rationality (IR). Therefore, the optimal contract under the condition of information symmetry could be obtained by solving the following optimal problem

$$
\left\{\begin{array}{l}
\max _{\alpha, \beta, e} E v=-\alpha+(1-\beta) k e \\
\text { s.t. (IR) } \alpha+\beta k e-b e^{2} / 2-\rho \beta^{2} \sigma^{2} / 2 \geq \bar{w}
\end{array}\right.
$$

The equal-sign in constraint condition of IR is ture in the above Formula (8) under the optimal circumstances of information symmetry, because it is not necessary for principal to pay agent more when information is symmetric. Then the optimal problem of Formula (8) could have another expression as following

$$
\max _{\beta, e}\left(k e-b e^{2} / 2-\rho \beta^{2} \sigma^{2} / 2-\bar{w}\right)
$$

To solve first order condition of the optimal problem in Equation (9), the expressions of Pareto optimal hardworking level $\left(e^{*}\right)$ and Pareto optimal incentive intensity $\left(\beta^{*}\right)$ could be gotten as following

$$
e^{*}=k / b, \beta^{*}=0,
$$

Substituting the equation of IR in the Formula (8) with the above results in the Formula (10), the expression of optimal fixed salary $\left(\alpha^{*}\right)$ under the condition of information symmetry could be obtained

$$
\alpha^{*}=\bar{w}+k^{2} / 2 b
$$

2) Optimal contract under the condition of information asymmetry

The level of hardworking of agent could not be observed by principal under the condition of asymmetric information. The incentive compatibility (IC) of agent at this moment does work. The maximization model of expected utility function of agent could be established as following 


$$
\max _{e} E u=\max _{e} W=\alpha+\beta k e-b e^{2} / 2-\rho \beta^{2} \sigma^{2} / 2
$$

For any given incentive contract, agent always selects an optimal hardworking level to maximize expected utility function. According to Mirrlees (1974) [12] and Holmstrom (1979) [10], the constraint of incentive compatibility (IC) could be replaced by first order condition of maximization model of expected utility function of agent. For the Formula (12), first order condition of maximization is $\frac{\partial E u}{\partial e}=\beta k-b e=0$. Solving the equation, the expression of hardworking level under the condition of information asymmetry could be gained, and the constraint of incentive compatibility (IC) could also be described as the expression

$$
\text { (IC): } e=\beta k / b
$$

Therefore, the optimal contract under asymmetric information should satisfy the solution of the following conditions

$$
\left\{\begin{array}{l}
\max _{\alpha, \beta} E v=-\alpha+(1-\beta) k e \\
\text { s.t. (IR) } \alpha+\beta k e-b e^{2} / 2-\rho \beta^{2} \sigma^{2} / 2 \geq \bar{w} \\
\text { (IC) } e=\beta k / b
\end{array}\right.
$$

Supposing that principal and agent are rational-economic, the equal-sign in constraint condition of IR is true in the Formula (14) when designing the optimal contract. Substituting the target function of the Formula (14) with the expressions of IR and IC, the optimal condition of the Formula (14) could be reformulated by

$$
\max _{\beta} \beta k^{2} / b-\beta^{2} k^{2} / 2 b-\rho \beta^{2} \sigma^{2} / 2-\bar{w}
$$

and first order condition of it could be expressed as $k^{2} / b-\beta k^{2} / b-\rho \beta \sigma^{2}=0$, then the share of output that university provides to UACO (namely incentive intensity) is

$$
\beta=\frac{k^{2}}{k^{2}+b \rho \sigma^{2}}
$$

Putting expressions of Formulas (15) and (13) into the equal equation of IR in Formula (14), the expression of fixed salary $(\alpha)$ under the condition of information asymmetry could be gained as

$$
\alpha=\bar{w}-\left(k^{2}-b \rho \sigma^{2}\right) / 2 b\left(1+b \rho \sigma^{2} / k^{2}\right)^{2}
$$

Consequently, the optimal contracts under information symmetry and asymmetry are listed in Table 1. fol- lowing the synthetic results of the above analysis.

\section{Analysis and Results}

The results will be analyzed from two sides of incentive contract and university revenue. The efficiency of achie-
Table 1. The design of incentive contracts of UACO under the conditions of symmetric and asymmetric information

\begin{tabular}{ccc}
\hline & $\begin{array}{c}\text { Information } \\
\text { symmetry }\end{array}$ & Information asymmetry \\
\hline $\begin{array}{c}\text { Hard- } \\
\text { working } \\
\text { level }\end{array}$ & $e^{*}=k / b$ & $e=\beta k / b$ \\
$\begin{array}{c}\text { Share of } \\
\text { output }\end{array}$ & $\beta^{*}=0$ & $\beta=k^{2} /\left(k^{2}+b \rho \sigma^{2}\right)$ \\
$\begin{array}{c}\text { Fixed } \\
\text { salary }\end{array}$ & $\alpha^{*}=\bar{w}+k^{2} / 2 b$ & $\alpha=\bar{w}-\left(k^{2}-b \rho \sigma^{2}\right) / 2 b\left(1+b \rho \sigma^{2} / k^{2}\right)^{2}$ \\
\hline
\end{tabular}

vements transformation in universities is of brutally vital importance for the outputs of UACO and the revenue of university, so these latter two parts will be equivalent to the efficiency of achievements transformation in the following analysis.

\subsection{Analysis of Incentive Contracts}

Compared the incentive contracts under the conditions of information symmetry and information asymmetry, the following results could be brought to:

Result 1: Incentive mechanism should be introduced in the salaries of UACO to enhance the efficiency of achievements commercialization in universities, for example implementing the wage system comprised fixed salaries and efficiency-related wages.

According to the incentive contract under the condition of asymmetric information, the share of outputs that UACO should be provided is $\beta=k^{2} /\left(k^{2}+b \rho \sigma^{2}\right)$. Here $0<\beta<1$ because $b, \rho, \sigma^{2}>0$, that is, to get the best incentive effectiveness, $k^{2} /\left(k^{2}+b \rho \sigma^{2}\right)$ unit should be provided to UACO if 1 unit output value of achievements commercialization is produced by UACO. From this point of view, the unitary fixed wage system implemented for a long time has seriously hindered the advancement of achievements transformation, and it is urgent for universities to reform the wage system of UACO.

Result 2: When the work ability of UACO is higher (larger $k$ ), or the willingness of working hard is stronger (smaller $b$ ), or the degree of risk aversion of UACO is smaller (smaller $\rho$ ), or outside uncertain factors are smaller (smaller $\sigma^{2}$ ), the wage system of lower fixed salary plus higher proportion of efficiency-related wage could be more effective for UACO to work hard and to boost the efficiency of commercialization. In certain circumstances, the wage mechanism only for efficiencyrelated wage, even that state of it which we term zero fixed salary, could be adopted.

The reason is that, according to Formula (15), first-order derivatives of $\beta$ respectively satisfy the conditions of $\partial \beta / \partial k=2 k b \rho \sigma^{2} /\left(k^{2}+b \rho \sigma^{2}\right)^{2}>0, \partial \beta /$ $\partial b<0, \partial \beta / \partial \rho<0, \partial \beta / \partial \sigma^{2}<0$, (the above calcula- 
tions are omitted here). Those first-order derivatives show that, the share of outputs $(\beta)$ is a monotone increasing function to the work ability of $\operatorname{UACO}(k)$, and is a monotone minus function to the willingness of working hard $(b)$, a monotone minus function to the degree of risk aversion $(\rho)$, a monotone minus function to outside uncertain factors $\left(\sigma^{2}\right)$. According to Formula (16), $\alpha<\bar{w}$ when $k^{2}>b \rho \sigma^{2}$, that is, the fixed salary could be below to conservative income for agent when certain condition is satisfied. Furthermore, $\alpha=0$ when $k^{2}=\bar{w}+b \rho \sigma^{2}$, it means that, the condition of zero fixed salary is happened. Certainly, the proportion of outputs required to share would be very high.

Remarkably, zero fixed salary is a state of fully- marketing operation that UACO are in a high degree of autonomy, or even become an independent legal entity detached from universities. It is an operating pattern of UACO worth of being probed into.

Result 3: The level of hardworking of UACO under the condition of asymmetric information is strictly less than that of symmetric information

It is because $0<\beta<1$, so $e=\beta k / b<k / b$, that is $e<e^{*}$.

The result provides a rational explanation for the current states that it is lack of working enthusiasm and lack of active action of hunting for market demands in UACO. It is further verified that incentive measures should be drawn out to encourage UACO work hard to promote the efficiency of achievements commercialization, especially under the circumstances of information asymmetry.

Result 4: Under the condition of information symmetry, UACO could be only paid for fixed salary because of

$\beta^{*}=0$. When fixed salary exactly equals to conservative income plus the cost of hardworking (that is $\alpha^{*}=\bar{w}+k^{2} / 2 b$ ), a desired optimal hardworking level of universities could be reached, and Pareto optimal risk apportion and optimal hardworking level could be realized simultaneously.

\subsection{Analysis of University Revenue (Efficiency of Commercialization)}

Connecting equations of (13), (14) and (15), the expression Formula (18) of university revenue ( $E^{a} v$ ) under the condition of asymmetric information could be obtained, and substituting Formula (8) with Formula (10), then we can get the expression Formula (17) of university revenue $\left(E^{s} v\right)$ under the condition of symmetric information. The results after collecting the forms could be seen in Table 2.

The following results could be gotten from Formula (17) and (18).

Result 5: The working ability of UACO is of great im-
Table 2. University revenues under the conditions of symmetric and asymmetric information

\begin{tabular}{lc}
\hline \multicolumn{2}{c}{ University revenue } \\
\hline Information symmetry & $E^{s} v=\frac{k^{2}}{2 b}-\bar{w}$ \\
Information asymmetry & $E^{a} v=\frac{k^{4}}{2 b\left(k^{2}+b \rho \sigma^{2}\right)}-\bar{w}$ \\
\hline
\end{tabular}

portance to the efficiency of commercialization for universities. The stronger the working ability, the more revenue is produced, then the higher efficiency of commercialization is taken place. Furthermore, a vital important result is that, the efficiency of achievements commercialization has squared forward growth relation with working ability of UACO.

It is because of

$$
\frac{\partial E^{a} v}{\partial k^{2}}=\frac{k^{4}+2 k^{2} b \rho \sigma^{2}}{2 b\left(k^{2}+b \rho \sigma^{2}\right)^{2}}>0,
$$

that is, the efficiency of achievements commercialization $\left(E^{a} v\right)$ is a monotone increasing function to square of working ability $\left(k^{2}\right)$.

What we learn from result 5 is that, it is need to adjust staff structure of UACO, to stress importance of technical ability, marketing skills and administrative ability for officers of UACO in China, and UACO managers should have all these abilities and skills.

Result 6: The efficiency of achievements commercialization is directly proportional to the willingness of hardworking of UACO, and is inversely proportional to the degree of risk aversion of UACO and to outside uncertain factors.

It is because the efficiency of achievements commercialization of universities $\left(E^{a} v\right)$ is a monotone minus function to willingness of working hard $(b)$, to risk aversion degree ( $\rho$ ), and to outside uncertain factors $\left(\sigma^{2}\right)$.

The revelation of this result is that, for the enhancement of commercialization efficiency of universities, the breakthrough points of it could also be from correcting the working attitudes and reducing the mood of risk aversion of UACO officers. Governments at all levels and universities should create a favorable atmosphere for achievements commercialization of universities, and reduce the adverse impact of outside uncertain factors on the commercialization of research findings in universities.

\section{Conclusions}

The value of this paper is that, a principal-agent relation between university and UACO is analyzed, and the optimal incentive contract designing model is proposed on the question of enhancing the efficiency of universities 
achievements commercialization. The results show that, the efficiency of universities achievements commercialization has a squared forward growth relation with UACO working ability, and it is directly proportional to willingness of hardworking of UACO, and is inversely proportional to risk aversion degree of UACO and to outside uncertainty. The level of hardworking of UACO under the condition of information asymmetry is strictly less than that of information symmetry. For the enhancement of commercialization efficiency, universities need to set up incentive mechanism in the wage system of UACO, and to determinate optimal fixed salary and incentive intensity on the basis of UACO working ability, willingness of hardworking, degree of risk aversion and outside uncertain factors.

In addition, the tentative idea of fully-marketing operation pattern for UACO that produced from zero fixed salary, and a series of problem initiated from it, for instance, the pattern is feasible under what kind of circumstance and how does the patter work, are all worth of being discussed further.

\section{Acknowledgements}

This research is supported by the National Natural Science Foundation of China (No. 70772074) and National Social Science Foundation of China (No. BIA090049). The authors want to give their acknowledgement to Professor Liu Guoxin and Doctor Yan Junzhou who gave valuable comments on the paper.

\section{REFERENCES}

[1] C. M. Leitch and R. T. Harrison, "Maximising the potential of university spin-outs: The development of secondorder commercialization activities,” R\&D Management, Vol. 35, No. 3, pp. 257-272, 2005.

[2] C. O'Gorman, O. Byrne, and D. Pandya, "How scientists commercialize new knowledge via entrepreneurship,"
Journal of Technology Transfer, Vol. 1, pp. 23-43, 2008.

[3] D. S. Siegel, D. A. Waldman, L. E. Atwater and A. N. Link, "Toward a model of the effective transfer of scientific knowledge from academicians to practitioners: Qualitative evidence from the commercialization of university technologies,” Journal of Engineering and Technology Management, Vol. 21, No. 2, pp. 115-142, 2004.

[4] P. M. Swamidass and V. Vulasa, "Why university inventions rarely produce income? Bottlenecks in university technology transfer," Journal of Technology Transfer, Vol. 34, No. 4, pp. 343-363, 2009.

[5] W. Chapple, A. Lockett, D. Siegel, and M. Wright, “Assessing the relative performance of UK university technology transfer offices: Parametric and non-parametric evidence,” Research Policy, Vol. 34, No. 3, pp. 369-384, 2005.

[6] G. D. Markman, P. T. Gianiodis, and P. H. Phan, "Supply-side innovation and technology commercialization," Journal of Management Studies, Vol. 46, No. 4, pp. 625649, 2009.

[7] W. Zhang, "Game theory and information economics," Shanghai, Shanghai People's Publishing House (in Chinese), pp. 238-239, 2004.

[8] S. Xie, "Economic game theory," Shanghai, Fudan University Press (in Chinese), pp. 137-139, 2002.

[9] J. Mirrlees, "The optimal structure of authority and incentives within an organization,” Bell Journal of Economics, Vol. 7, No. 8, pp. 105-131, 1976.

[10] B. Holmstrom, “Moral hazard and observability,” Bell Journal of Economics, Vol. 10, No. 12, pp. 74-91, 1979.

[11] X. Huang, X. Tao, and W. Xing, "Design of energy saving contract based on principal-agent theory," Industrial Engineering Journal (in Chinese), Vol. 12, No. 4, pp. 19-22, 2009.

[12] J. Mirrlees, "Notes on welfare economics, information and uncertainty,” In Essays on Economic Behavior under Uncertainty, edited by M. Balch, D. McFadden and S. Y. Wu, Amsterdam: North-Holland, 1974. 